\title{
Analisis Arsen Pada Berbagai Macam Beras Putih Dan Hasil Tanakannya Secara Spektrofotometri Serapan Atom
}

\author{
Arsent Analysis On Various Kinds Of White And Rice Results Ask By Atomic Absorption \\ Spectrophotometry
}

\author{
Sanggam Dera Rosa Tampubolon \\ ${ }^{1}$ Program Studi Teknologi Hasil Pertanian, UNIKA Santo Thomas Medan \\ email : rosatampubolon031969@gmail.com
}

\begin{abstract}
This study aims to determine the arsenic content of various types of rice, the effect of the type of water on the arsenic content of the crops used for cooking rice, and to find out whether there are differences in arsenic levels in various types of rice circulating in the city of Medan. The research was conducted at the Laboratory of Agricultural Product Processing and Management, Agricultural Product Technology Study Program, Faculty of Agriculture, St. Catholic University. Thomas Medan. The samples used in this study were AA white rice, kukubalam, IR-64, Cap Pocy. This research was conducted in two stages, the first stage starting with the preparation of rice samples obtained from various types of rice circulating around the city of Medan, then mashed so that they become rice flour. The second stage is the rice planting process, after being cooked then refining it again. The arsenic levels were analyzed quantitatively in the two types of samples using an atomic absorption spectrophotometer at a wavelength of $193.7 \mathrm{~nm}$. Based on the results of the study, the highest arsenic levels were found in AA brand rice, namely $0.1293 \mathrm{mg} / \mathrm{kg}$ and the lowest in Cap Pocy rice, namely $0.0878 \mathrm{mg} / \mathrm{kg}$. The highest reduction in arsenic content in AA rice was cooked using RO water, namely $26.52 \%$ compared to tap water, which was $19.52 \%$.
\end{abstract}

Keywords: arsenic, rice, spectrophotometry, tannants

\begin{abstract}
ABSTRAK
Penelitian ini bertujuan untuk mengetahui kadar arsen dari berbagai jenis beras, pengaruh jenis air terhadap kadar arsen hasil tanakannya yang digunakan untuk menanak beras, dan untuk mengetahui apakah ada perbedaan kadar arsen pada berbagai jenis beras yang beredar di kota Medan. Penelitian dilakukan di Laboratorium Pengolahan dan Pengelolaan Hasil Pertanian, Program Studi Teknologi Hasil Pertanian, Fakultas Pertanian, Universitas Katolik St. Thomas Medan. Sampel yang digunakan dalam penelitian ini adalah beras putih AA, kukubalam, IR-64, Cap Pocy. Penelitian ini dilakukan dengan dua tahapan, tahap pertama dimulai dengan penyiapan sampel beras yang diperoleh dari berbagai jenis beras yang beredar di sekitar kota Medan, kemudian dihaluskan sehingga menjadi tepung beras. Tahap kedua dilakukan proses penanakan pada beras, setelah tanak kemudian dihaluskan kembali.
\end{abstract}


Dilakukan analisa kadar arsen secara kuantitatif pada kedua jenis sampel tersebut dengan menggunakan alat spektrofotometer serapan atom pada panjang gelombang 193,7 nm. Berdasarkan hasil penelitian maka diperoleh kadar arsen tertinggi ditemukan pada beras merek AA yaitu $0,1293 \mathrm{mg} / \mathrm{kg}$ dan terendah pada beras Cap Pocy yaitu $0,0878 \mathrm{mg} / \mathrm{kg}$. Penurunan kadar arsen pada beras AA yang tertinggi ditanak dengan menggunakan air RO yaitu $26,52 \%$ dibandingkan menggunakan air keran, yaitu $19,52 \%$.

Kata kunci: arsen, beras, spektrofotometri, tanak

\section{PENDAHULUAN}

Arsen merupakan bahan kimia dan metaloid paling beracun yang ditemukan di alam yang dapat menyebabkan toksisitas dan karsinogenik, bahkan pada konsentrasi rendah (Darmono, 2001). Efek arsen berhubungan dengan perubahan dalam gastrointestinal, kardiovaskular, hematologi, paru, saraf, imunologi, reproduksi dan efek jangka panjang arsen dapat menyebabkan kanker (IARC, 2012).

Beras adalah sumber utama paparan arsen bagi manusia saat ini. Makanan adalah media yang potensial dari paparan arsen dan kandungan arsen dalam beras dikaitkan dengan kontaminasi tanah, pemupukan, dan penggunaan pestisida (Lynch, et al. 2014).

Kadar arsen beras merah lebih tinggi dibandingkan dengan beras putih tetapi konsentrasi arsen pada beras putih juga perlu mendapat perhatian (Andrea, et al. 2008).

Di Indonesia belum pernah dilakukan penelitian dan pengujian mengenai kandungan arsen dalam beras, selain itu belum adanya regulasi dan standar yang ditetapkan oleh Badan Pengawas Obat dan Makanan Ripublik Indonesia. Hal ini yang menjadi dasar peneliti untuk melakukan pengujian terhadap kadar arsen dalam beras yang beredar dikota Medan, meliputi beras yang beredar di pasar tradisional dan pasar swalayan.

Pada penelitian ini dilakukan dengan menggunakan spektrofotometri serapan atom karena mempunyai kepekaan yang tinggi (batas deteksi kurang dari 0,01 ppm) dan pelaksanaanya relatif cepat dan sederhana, dan interfrensi rendah (Gandjar dan Rohman, 2007). Berdasarkan uraian diatas peneliti memiliki tujuan antara lain untuk mengetahui kadar arsen dari berbagai jenis beras yang beredar di kota Medan, untuk mengetahui apakah kadar arsen dalam beras yang beredar di kota Medan masih memenuhi standart yang ditetapkan oleh WHO, untuk mengetahui pengaruh jenis air terhadap kadar arsen hasil tanakannya yang digunakan untuk menanak beras, dan untuk mengetahui apakah ada perbedaan kadar arsen pada berbagai jenis beras yang beredar di kota Medan.

\section{Bahan}

Sampel yang digunakan adalah beras diperoleh dari beberapa pasar tradisional dan swalayan di kota medan. Beras yang digunakan sebagai sampel terdiri dari 4 merek yaitu beras putih AA, kukubalam, IR64, Cap Pocy. Bahan kimia yang digunakan antara lain aqua demineralisata, air keran, air RO dan bahan berkualitas pro analisis keluaran E. Merck yaitu asam nitrat $65 \%$, larutan baku arsen $1000 \mu \mathrm{g} / \mathrm{ml}$, asam klorida $37 \%$.

\begin{abstract}
Alat
Alat-alat yang digunakan dalam penelitian ini adalah wajan, spatula, kompor, blender, pisau, ayakan, oven, sendok goreng, gelas, saringan, gelas piala, batang pengaduk, termometer, sendok makan, alumunium foil, timbangan, kain saring, erlenmeyer, tabung reaksi, pipet tetes,
\end{abstract}


beaker glass.

\section{Prosedur Penelitian}

\section{Pengambilan Sampel}

Metode pengambilan sampel dilakukan secara purposif dimana sampel ditentukan atas dasar pertimbangan bahwa semua jenis beras yang dijual di pasar tradisional Medan adalah homogen.

\section{Penyiapan Sampel}

Beras sebanyak $100 \mathrm{~g}$, kemudian dicuci dengan air mengalir dan ditiriskan sampai kering. Beras digiling hingga menggunakan mesin penggiling menjadi tepung beras.

\section{Hasil Tanakan}

Beras sebanyak $150 \mathrm{~g}$ dicuci sebanyak 3 kali pengulangan masing-masing dengan air keran atau air RO. Kemudian, beras dimasukkan kedalam rice cooker dengan menggunakan masing-masing air keran dan air RO, dimana perbandingan beras dengan air keran atau air RO adalah 1 : 2 Setelah tanak, didinginkan lalu ditimbang 100 g. Kemudian diblender hingga halus.

\section{Analisis Arsen pada Beras}

Sampel ditimbang sebanyak $0,5 \mathrm{~g}$ lalu dimasukan kedalam vessel, ditambahkan $5 \mathrm{ml} \mathrm{HNO}_{3} 65 \%$ dan $3 \mathrm{ml} \mathrm{HCI}$. Lalu didiamkan selama 10 menit agar sampel larut. Vessel dimasukan kedalam microwave dengan suhu $180^{\circ} \mathrm{C}$ selama 30 menit hingga dekstruksi terjadi sempurna yang ditandai dengan diperolehnya cairan jernih. Kemudian hasil destruksi didinginkan dan dimasukkan kedalam labu ukur $50 \mathrm{ml}$ dan dicukupkan dengan aqua demineralisata sampai $50 \mathrm{ml}$ dan disaring dengan kertas whatmann no 41.

\section{Analisis Kuantitatif}

\section{Pembuatan Kurva Kalibrasi}

Larutan Baku Induk Arsen (1000 $\mu \mathrm{g} / \mathrm{ml}$ ) dipipet $10 \mathrm{ml}$ ke dalam labu tentukur $100 \mathrm{ml}$ dan dicukupkan hingga garis tanda dengan aqua demineralisata (konsentrasi 100 $\mu \mathrm{g} / \mathrm{ml}$ ). Kemudian dipipet $5 \mathrm{ml}$ lalu dimasukkan ke dalam labu tentukur $500 \mathrm{ml}$, kemudian diencerkan dengan aqua demineralisata (konsentrasi $1 \mu \mathrm{g} / \mathrm{ml}$ ). Dipipet kembali $(0 ; 0,5 ; 1 ; 1,5 ; 2 ; 2,5) \mathrm{ml}$ dimasukkan kedalam labu ukur $100 \mathrm{ml}$ dan dicukupkan hingga garis tanda dengan aqua demineralisata (larutan ini mengandung $(0$; $0,005 ; 0,01 ; 0,015 ; 0,02 ; 0,025 \mu \mathrm{g} / \mathrm{ml})$ dan diukur pada panjang gelombang 193,7 nm.

Kadar arsen dalam sampel dapat dihitung dengan cara:

$\operatorname{kadar}(\mu \mathrm{g} / \mathrm{g})=\frac{\mathrm{X}(\mu \mathrm{g} / \mathrm{ml}) \times \mathrm{V}(\mathrm{ml}) \times \mathrm{Fp}}{\mathrm{W}(\mathrm{g})}$

Keterangan:

$\mathrm{X}=$ Konsentrasi analik dalam larutan sampel

$\mathrm{V}=$ Volume total larutan sampel yang diperiksa

$\mathrm{Fp}=$ Faktor pengenceran

$\mathrm{W}=$ Berat sampel

\section{HASIL DAN PEMBAHASAN}

\section{Kadar Arsen dalam Beras dan Hasil Tanakannya}

Konsentrasi arsen dalam sampel ditentukan berdasarkan persamaan garis regresi kurva kalibrasi larutan baku arsen. Kadar arsen dalam beras dan hasil tanakannya serta penurunan kadar arsen dapat dilihat pada Tabel 1. Berdasarkan pada tabel 1 ini dapat kita lihat bahwa perbedaaan kadar arsen setiap merek beras dimana kadar arsen tertinggi terdaapat pada beras yang bermerek AA yaitu sebesar 0.,1293 mg/kg, sedangkan kadar arsen yang paling terendah terdapat pada merek beras Cap Pocy yaitu $0,0878 \mathrm{mg} / \mathrm{kg}$, masih berada dibawah yang ditetapkan oleh $\mathrm{WHO}$ yaitu $0,3 \mathrm{mg} / \mathrm{kg}$.

Berdasarkan Gambar 1 menunjukkan terdapat perbedaan kadar arsen pada beras dan hasil tanakannya. Ada 4 merek beras yang diuji yaitu beras AA, beras IR-64, beras kukubalam dan cap poci. Kadar arsen tertinggi $0,1293 \mathrm{mg} / \mathrm{kg}$ terdapat pada beras AA, dimana kadar ini sudah melebihi standar WHO (2014) yaitu $0,3 \mathrm{mg} / \mathrm{kg}$. 
sedangkan kadar arsen terendah 0,0878 $\mathrm{mg} / \mathrm{kg}$ yang terdapat pada beras Cap Poci. Banyak faktor yang mempengaruhi tingginya kadar arsen pada beras. Jika kadar arsen pada air irigasi dan lingkungan beras tinggi maka kadar arsen pada beras juga tumbuh telah terkontaminasi oleh arsen juga menyebabkan perbedaan kadar arsen.

Pada penelitian ini proses penanakan beras menggunakan 2 jenis air, yaitu air RO dan air kran. Air yang digunakan dapat mengurangi kadar arsen pada hasil tanakannya. Pada beras IR-64 setelah ditanak menggunakan air RO mengalami penurunan kadar arsen sebesar 24,97 \% sedangkan setelah ditanak menggunakan air keran mengalami penurunan kadar sebesar $17,49 \%$ pada beras kukubalam setelah ditanak menggunakan air RO kadar arsen mengalami penurunan kadar arsen $5,01 \%$ sedangkan setelah ditanak menggunakan air keran mengalami penurunan kadar arsen sebesar 3,08 \%.

Pada beras AA setelah ditanak menggunakan air RO kadar arsen mengalami penurunan kadar sebesar 26,52 $\%$ sedangkan setelah ditanak menggunakan air keran mengalami penurunan kadar sebesar $19,52 \%$. Pada beras cap poci kadar arsen setelah ditanak menggunakan air RO kadar arsen mengalami penurunan kadar sebesar $13,55 \%$ sedangkan setelah ditanak dengan air keran mengalami penurunan kadar sebesar $4,1 \%$.

Tabel 1. Kadar Arsen dalam Beras dan Hasil Tanakannya

\begin{tabular}{|c|c|c|c|c|c|c|}
\hline \multirow{5}{*}{ No. } & \multirow{5}{*}{ Sampel } & \multicolumn{3}{|c|}{ Kadar Arsen (mg/kg) } & \multicolumn{2}{|c|}{$\begin{array}{c}\text { Penurunan Kadar } \\
(\%)\end{array}$} \\
\hline & & \multirow{4}{*}{$\begin{array}{l}\text { Sebelum } \\
\text { Ditanak }\end{array}$} & Setelah & Setelah & Setelah & Setelah \\
\hline & & & \multirow{3}{*}{$\begin{array}{l}\text { Ditanak } \\
\text { dengan Air } \\
\text { RO }\end{array}$} & \multirow{3}{*}{$\begin{array}{l}\text { Ditanak } \\
\text { dengan Air } \\
\text { Kran }\end{array}$} & Ditanak & Ditanak \\
\hline & & & & & dengan & dengan \\
\hline & & & & & Air RO & Air Kran \\
\hline \multirow[t]{2}{*}{1.} & Beras & $0,0949 \pm 0,1286$ & $0,0712 \pm 0,0496$ & $0,0783 \pm 0,0390$ & 24,97 & 17,49 \\
\hline & IR-64 & & & & & \\
\hline \multirow[t]{2}{*}{2.} & Beras & $0,0937 \pm 0,1262$ & $0,089 \pm 0,1202$ & $0,0909 \pm 0,1377$ & 5,01 & 3,08 \\
\hline & Kukubalam & & & & & \\
\hline \multirow[t]{2}{*}{3.} & Beras & $0,1293 \pm 0,4143$ & $0,0950 \pm 0,0825$ & $0,1044 \pm 0,0326$ & 26,52 & 19,52 \\
\hline & $\mathrm{AA}$ & & & & & \\
\hline 4. & $\begin{array}{l}\text { Beras Cap } \\
\text { Poci }\end{array}$ & $0,0878 \pm 0,3876$ & $0,0759 \pm 0,0660$ & $0,0842 \pm 0,0597$ & 13,55 & 4,1 \\
\hline
\end{tabular}

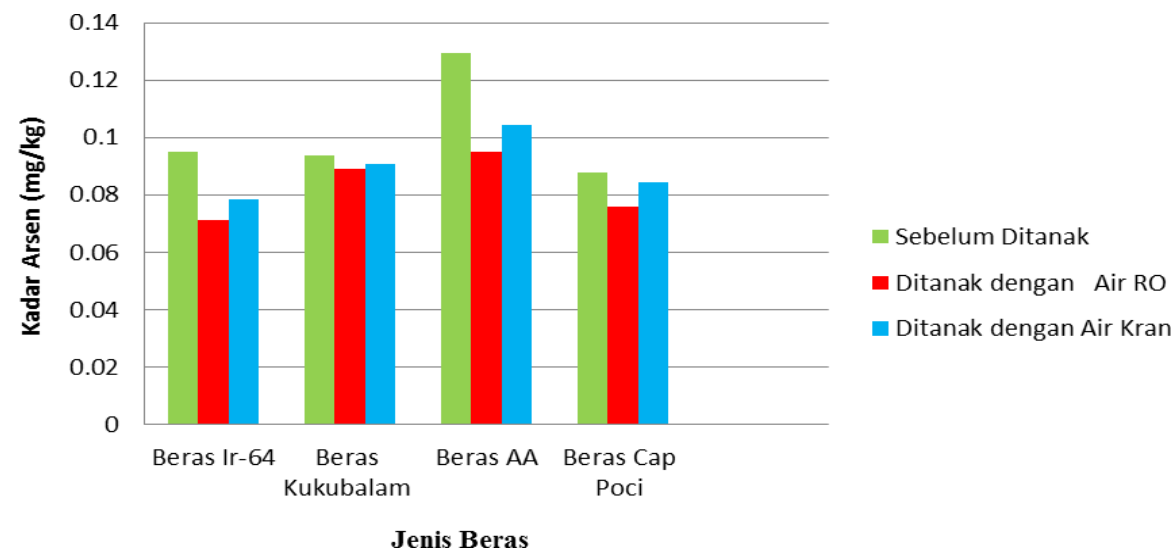

Gambar 1. Diagram pengaruh proses penanakan menggunakan air RO dan air kran terhadap kadar arsen dalam berbagai jenis beras 
Berdasarkan pada tabel 1 ini dapat kita lihat bahwa perbedaaan kadar arsen setiap merek beras dimana kadar arse tertinggi terdaapat pada beras yang bermerek AA yaitu sebesar 0.,1293 mg/kg, dan sedangnkan kadar arsen yang paling terandah terdapat pada merek beras Cap Pocy yaitu $0,0878 \mathrm{mg} / \mathrm{kg}$, masih berada dibawah yang ditetapkan olrh WHO yaitu $0,3 \mathrm{mg} / \mathrm{kg}$.

Berdasarkan Gambar 1 menunjukkan terdapat perbedaan kadar arsen pada beras dan hasil tanakannya. Ada 4 merek beras yang diuji yaitu beras AA, beras IR- 64, beras kukubalam dan cap poci. Kadar arsen tertinggi $0,1293 \mathrm{mg} / \mathrm{kg}$ terdapat pada beras AA, dimana kadar ini sudah melebihi standar WHO (2014) yaitu $0,3 \mathrm{mg} / \mathrm{kg}$. Sedangkan kadar arsen terendah $0,0878 \mathrm{mg} / \mathrm{kg}$ yang terdapat pada beras Cap Poci .

Banyak faktor yang mempengaruhi tingginya kadar arsen pada beras. Jika kadar arsen pada air irigasi dan lingkungan beras tinggi maka kadar arsen pada beras juga tinggi, begitu sebaliknya. Hal ini juga berhubungan erat dengan perbedaan genetic dari beras serta tempat lingkungan beras tumbuh telah terkontaminasi oleh arsen juga menyebabkan perbedaan kadar arsen.

Pada penelitian ini, proses penanakan beras menggunakan 2 jenis air yaitu air RO dan air kran. Air yang digunakan dapat mengurangi kadar arsen pada hasil tanakannya. Pada beras IR-64 setelah ditanak menggunakan air RO mengalami penurunan kadar arsen sebesar 24,97\% sedangkan setelah ditanak menggunakan air keran mengalami penurunan kadar sebesar $17,49 \%$ pada beras kukubalam setelah ditanak menggunakan air RO kadar arsen mengalami penurunan kadar arsen 5,01\% sedangkan setelah ditanak menggunakan air keran mengalami penurunan kadar arsen sebesar 3,08\%.

Pada beras AA setelah ditanak menggunakan air RO kadar arsen mengalami penurunan kadar sebesar 26,52
$\%$ sedangkan setelah ditanak menggunakan air keran mengalami penurunan kadar sebesar 19,52\%. Pada beras cap poci kadar arsen setelah ditanak menggunakan air RO kadar arsen mengalami penurunan kadar sebesar 13,55\% sedangkan setelah ditanak dengan air keran mengalami penurunan kadar sebesar $4,1 \%$.

Penelitian sebelumnya juga telah dilakukan, berdasarkan penelitian Palt, et al.(2009) , menunjukkan bahwa proses penanakan dapat menurunkan kadar arsen hingga $8 \%-58 \%$ dan pada penelitian ini menggunakan air dengan kadar arsen yang rendah. Selain itu, penelitian Sengupta, et al. (2006), juga menunjukkan bahwa proses penanakan dapat mengurangi kadar arsen hingga $28 \%$ dan pada penelitian ini menggunakan sumber air (air keran dan air $\mathrm{RO})$.

Demikian pula penelitian Halder, et al. (2004), menunjukkan bahwa proses penanakan yang menggunakan air keran dapat menurunkan kadar arsen dari 7,5 \%$66,3 \%$. Berdasarkan penelitian Paravenhvar (2015), menunjukkan bahwa pada beras yang telah ditanak dapat mengurangi kadar arsen sebesar 2,8\%-13,8 $\%$.

Pada penelitian ini dapat dilihat bahwa penurunan kadar arsen terbesar yaitu setelah ditanak dengan menggunakan RO, yaitu $16,06 \%$. Air RO adalah air yang tidak mengandung mineral dan juga tidak mengandung zat-zat berbahaya baik zat beracun ataupun bakteri. Hal ini disebabkan karena air RO tidak mengandung mineral dan pencemaran yang berbahaya bagi kesehatan. Selain itu, air RO juga memiliki kemampuan untuk menyerap logam-logam toksis karena kandungan mineral kalsium dan magnesium sangat rendah dalam air RO (Silalahi, 2014). Maka dalam hal ini, arsen yang ada dalam beras akan lebih mudah diserap oleh air RO dibandingkan air keran dikarenakan kandungan mineral pada air RO lebih rendah. SNI (2015) juga menetapkan persyaratan arsen maksimal pada air mineral alami $0,05 \mathrm{mg} / \mathrm{l}$ sedangkan 
pada air demineral adalah $0,01 \mathrm{mg} / \mathrm{l}$. Hal ini menyebabkan beras AA merupakan beras yang paling banyak mengandung arsen dibandingkan beras kukubalam, IR64, dan cap poci.

\section{Indeks Keamanan Arsen dalam Beras}

Perhitungan indeks keamanan arsen dalam beras berdasarkan WHO (2014) diperoleh melalui perhitungan asupan harian (Daily Intake) kemudian dilanjutkan perhitungan Excess Cancer Risk (ECR). Indeks keamanan arsen dalam beras dapat dilihat pada Tabel 2.

Berdasarkan Tabel 2. menunjukkan bahwa nilai ECR pada beras putih, beras cokelat, beras merah, dan ketan hitam lebih
Semakin tinggi konsentrasi maka nilai kecil dari 1 x 10-5, artinya dalam 100.000 penduduk tidak terdapat tambahan kasus kanker, maka beras tidak aman bila dikonsumsi 224 g selama 350 hari/tahun dalam jangka waktu 30 tahun oleh berat badan $60 \mathrm{~kg}$ atau kurang. Paparan arsen kronik dapat menyebabkan gangguan pada sistem biologis seperti pencernaan, pernapasan, kardiovaskular, hematopiek, endokrin, ginjal, saraf, dan reproduksi, yang akhirnya menyebabkan kanker. Asupan harian pada $1 \mathrm{mg}$ arsen dapat menyebabkan efek pada kulit dalam beberapa tahun.

Tabel 2. Indeks Keamanan Arsen dalam Beras

\begin{tabular}{llcccc}
\hline No. & Sampel & $\begin{array}{l}\text { Kadar } \\
\text { Arsen } \\
(\mathrm{mg} / \mathrm{kg})\end{array}$ & $\begin{array}{l}\text { Daily Intake } \\
(\mathrm{mg} / \mathrm{kg} / \mathrm{hari})\end{array}$ & $\begin{array}{l}\text { ECR } \\
(\text { Resiko kanker }) \\
(\mathrm{mg} / \mathrm{kg} / \mathrm{hari})\end{array}$ & $\begin{array}{l}\text { Syarat Aman } \\
\text { ECR }(< \\
\left.1 \times 10^{-5}\right)\end{array}$ \\
\hline 1. & Beras Putih & 0,0693 & $1 \times 10^{-5}$ & $1 \times 10^{-5}$ & Aman \\
2. & Beras Cokelat & 0,0830 & $1 \times 10^{-5}$ & $1 \times 10^{-5}$ & Aman \\
3. & Beras Merah & 0,3061 & $1 \times 10^{-5}$ & $1 \times 10^{-5}$ & Aman \\
4. & Ketan Hitam & 0,1091 & $1 \times 10^{-5}$ & $1 \times 10^{-5}$ & Aman \\
\hline
\end{tabular}

Catatan: Indeks keamanan arsen dalam beras dihitung berdasarkan konsumsi beras di Indonesia yaitu 224 g/hari/orang.

\section{KESIMPULAN}

Kadar arsen tertinggi ditemukan pada beras merek AA yaitu $0,1293 \mathrm{mg} / \mathrm{kg}$ dan terendah pada beras Cap Pocy yaitu $0,0878 \mathrm{mg} / \mathrm{kg}$. Kadar arsen dalam beras yang diperoleh dinyatakan aman untuk dikomsumsi karena berada dibawah batas yang ditetapkan WHO yaitu 0,3 $\mathrm{mg} / \mathrm{kg}$. Penurunan kadar arsen pada beras AA yang tertinggi ditanak dengan menggunakan air RO yaitu 26,52 \% dibandingkan menggunakan air keran yaitu 19,52\%.

\section{SARAN}

Disarankan kepada pemerintah dalam badan POM untuk melakukan regulasi persyaratan arsen pada beras dengan standar yang jauh lebih rendah yang ditetapkan WHO 0,3 $\mathrm{mg} / \mathrm{kg}$ untuk melindungi kesehatan masyarakat. Disarankan kepada peneliti selanjutnya, untuk membandingkan kadar arsen pada beras yang ditanak secara tradisional. 


\section{DAFTAR PUSTAKA}

Andrea, 2008. Cooking Rice in A High Water to Rice Ratio Reduces

Arsenic Contant. Joaurnal of Environmental Monitoring. 11(3): 41-44.

Cappel W.R., Abemathy C.O., Calderon., 2000. Arsenic Exposure and Health Effect IV.Proceeding of the Fourth International Confrence on Arsenic Exposure and Health Effects. California. Accesed on june 2000. 165-171

Darmono. 2001.Lingkungan Hidup dan Pencemaran, Hubungannya dengan Toksikologi Senyawa Logam. Hal 132. UI-Press. Jakarta Gandjar L. G, and Rohman, A., 2007, Kimia Farmasi Analisis. Pustaka Belajar, Yogyakarta

Harmita, 2006, Buku Ajar Analisis Fisikokimia. Depok: Departemen Farmasi FMIPA Universitas Indonesia, Depok.

International Agency for Research on Cancer., 2010, Some DrinkingWater Disinfectants and Contaminants, Including Arsen In Rice. Monographs on the Evaluation of the Carcinogenic Risks to Humans: 512.

Lynch, H.N., Greenberg, G.I., Pollock, M.C., Lewis, A.S. 2014. Comprehensive Evaluation of Inorganic Arsenic in Food and Considerations for Dietary Intake Analyses. The Journal Science Environment. 496(29): 299-313.

World Heald Organization., 2014, Codex Alimentarius Commission. Codex Comunitee On Contaminants In Foods: Eight Session: 9. Jakarta. 